\title{
Toward a Theoretical Framework for Information Science
}

\author{
Amanda Spink \\ The Pennsylvania State University
}

spink@ist.psu.edu

\begin{abstract}
Information Science is beginning to develop a theoretical framework for the modeling of users' interactions with information retrieval (IR) technologies within the more holistic context of human information behavior (Spink, 1998b). This paper addresses the following questions: (1) What is the nature of Information Science? and (2) What theoretical framework and model is most appropriate for Information Science? This paper proposes a theoretical framework for Information Science based on an explication of the processes of human information coordinating behavior and information feedback that facilitate the relationship between human information behavior and human interaction with information retrieval (IR) technologies (Web, digital libraries, etc.).
\end{abstract}

Keywords: feedback, information science, human information coordinating behavior

\section{Introduction}

\section{Nature of information science}

To begin, we examine: What is the nature of Information Science? Information Science seeks to understand the complex process that involves and requires a number of informationrelated activities: human information seeking and retrieving behaviors; organization of a collection of texts, and more recently images, sounds or multimedia, that bear some cognitive content; an intellectual representation of such texts, be it derived by humans directly or indirectly by a variety of algorithms; intellectual ways and means of searching and retrieval by users; and the systems and techniques to accomplish all of these. The complexity of human information seeking and retrieving is derived not only from these very difficult processes, but from the direct involvement of human generators and users of texts in information systems, bringing in cognitive, affective, social and situational (problem, task) variables.

In other words, Information Science is not only a technical but even more so a cognitive, social, and situational process. With the marriage of computers and telecommunications, Information

Material published as part of this journal, either on-line or in print, is copyrighted by the publisher of Informing Science. Permission to make digital or paper copy of part or all of these works for personal or classroom use is granted without fee provided that the copies are not made or distributed for profit or commercial advantage AND that copies 1) bear this notice in full and 2) give the full citation on the first page. It is permissible to abstract these works so long as credit is given. To copy in all other cases or to republish or to post on a server or to redistribute to lists requires specific permission and payment of a fee. Contact Editor@inform.nu to request redistribution permission.
Science is based on facilitating interactive information processes, involving information feedback and human information coordinating behaviors. All these concepts provide the building blocks for deriving a general framework for Informatics.

\section{Theoretical Framework}

Second, the paper deals with the question: What theoretical framework and model is most appropriate for Information Science? Information Science research is concerned with how humans create, seek, retrieve and use information; particularly human interactions with information systems that now include digital libraries and the Web. Information Science processes include human creating, seeking, retrieving and using information; particularly human interaction with information systems. Information Science focuses on many different processes that occur over time, including a human information problem that initiates information behavior related to a human problem state, cognitive state and knowledge state (Ingwersen, 1992, 1996), including information seeking behavior (Kuhlthau, 1993), human searching behavior with information retrieval (IR) systems (Saracevic, 1996,1997), with interactive issues such as feedback (Spink, 1998b; Spink \& Saracevic, 1998) and relevance (Spink, Greisdorf \& Bateman, 1998).

In other words, information seekers coordinate a number of elements, including their cognitive state, level of domain knowledge, and their understanding of their information problem, into a coherent series of activities that may include seeking, searching, interactive browsing and retrieving and constructing information (Kuhlthau, 1993). 
In particular, this paper introduces and elaborates on the concept of human information coordinating behavior (HICB) as an important linking process for Informatics that binds together the many processes involved in human information seeking and retrieving. The development of our understanding of information-related processes necessitates a theoretical and empirical explication of the important nature and role of HICB. The next section of the paper proposes a theoretical framework for the key process of human information coordination behavior.

\section{The Binding Process: Human Information Coordinating Behavior}

HICB is an integrating behavior that binds and draws together processes at the heart of Information Science. Human information coordination binds and draws together other processes at the heart of human information seeking and retrieving. Information Science research focuses on many different aspects of information coordinating behavior, including modeling human information behavior (Wilson, 1997), information seeking behavior (Kuhlthau, 1993), human searching behavior with IR systems (Saracevic, 1996, 1997; Belkin, Cool, Stein \& Theil, 1995; Ingwersen, 1992, 1996) and processes central to human information seeking and searching such as relevance (Spink, Greisdorf \& Bateman, 1998), feedback (Spink, 1997a,b), representation and interaction.

A growing number of researchers are working towards a more integrated view of human information seeking and searching (Spink, 1998b). However, without human coordination of various elements of the human information seeking and searching process there would be no process. Human information coordination behavior is not a phenomenon unfamiliar to the models and processes of concern to informatics. However, as an implicit process, its nature, manifestations and effects have not previously been explicitly investigated.

This paper proposes an integrating theoretical framework for the human process of information coordination as an integrating notion for Information Science. I propose that there exist various levels of human information coordination -

1. Information seeking level

2. Information searching (HCI) level

Humans cognitively coordinate their information seeking level behaviors with their information searching level (human-system interaction) behaviors; including the recognition and making sense of and cognitively articulating an information need or a gap in their knowledge. Humans then coordinate these processes to construct an information-seeking process. Coordination is also related to movement through a human information seeking process. Humans coordinate information in order to move through their information-seeking process. Part of the information-seeking process is the translation of their information prob- lem into a form that allows them to construct information from texts in the broadest sense. Bringing the elements of their information problem to an effective information-seeking and searching process is essential to an effective coordination process.

For example, a human is seeking information on her family history. She enters a library or begins to search the Web. To enable her information-seeking and searching process to move forward she must understand the dimensions of her information problem and coordinate her information seeking and searching processes to the degree that she is able to interact with the functional structure of the library or Web system. This coordination process between information problem and information-

seeking/searching process must take place before a user enters a keyword into the Web or begins to browse the library shelves.

The output of the Web search or the books found on the library shelves are coordinated through information feedback by the information-seeker with her information problem through various judgments of the relevance, magnitude and strategic aspects of the information system's output (Spink, 1997b).

Establishing and maintaining an effective information seeking and searching process requires humans to develop effective and coherent information coordinating behaviors and processes. In other words, information seekers must coordinate a number of elements, including their cognitive state, level of knowledge, their understanding of their information problem, into a coherent series of activities that may include seeking, searching, retrieving and using information. We know that hand-eye coordination is a physiological process humans develop from childhood. But, how do humans learn the process of coordinating their information needs into coherent processes of human information seeking and retrieving behaviors? The information feedback loop forms the basis of the looping HICB process. How do humans achieve coordination, including recognizing, making sense of and cognitively articulating an information need or gap in their knowledge, and construct and maintain an information seeking process? What is the relationship between information feedback and HICB?

The informational feedback loop of coordination behavior is one of the most penetrating fundamentals in the information sciences and the basis for a theory of interaction. An important theoretical foundation for the human information coordination process is information feedback. A basic issue confronting Information Science is the nature, manifestations and effects of feedback. In previous publications I reviewed the current state of feedback research in information science (Spink, 1997a,b; Spink, 1998a,b; Spink \& Losee, 1996; Spink \& Saracevic, 1998). Feedback, as a basic element of Information Science, is related to other basic elements including information, interpretation, representation, knowledge state, relevance, shifts and interaction. The process of information feedback (Spink \& Saracevic, 1998) facilitates human information seeking and searching 
(Spink, 1997a,b) and binds the human process of coordinating information seeking and searching.

Effective matching has been seen as the key to effective interaction between humans and information systems. However, information systems must do more than match - they must assist users to coordinate and facilitate effective human information coordination behaviors. Humans coordinate a loop of actions. Information coordination is a fundamental human initiated, facilitated and determined behavior. We are told that humans and information systems must collaborate. However, unless a human can coordinate, a collaboration with an information system may be ineffective. Human and information systems must also collaborate to facilitate an effective information coordination. However, coordination goes beyond collaboration - you may collaborate on one level, but not facilitate a coordination.

Exploration of HICB is crucial to the development of the field of Information Science and the design of more effective information systems. Human information coordination is a complex human process to model. Information system designers are in reality trying to facilitate information-coordinating behavior that allows humans to effectively coordinate their actions within the context of their information seeking process. The effectiveness of human information coordination has been partly determined by relevance measures such as precision and recall, and can also be measured by changes in humans' stages in their information seeking process (Spink, Greisdorf \& Bateman, 1998).

New information system effectiveness measures may be based on human information coordinating behaviors. Information coordination is a rich notion of active human information behaviors. HICB lends value to Information Science research by bringing together interdisciplinary concepts and integrating them into a concise model and framework for ongoing studies and development. The explication of the process of human information coordinating behavior is fundamental to the development of a theoretical framework and model for Informatics. The modeling of human information coordinating process, in relation to human information behaviors of seeking and searching, may assist in the development of information systems that more effectively enable humans to effectively coordinate their actions within the context of their information seeking processes.

\section{Further Issues}

Further important issues to examine include: How do humans coordinate the various elements of their information seeking and searching into a coherent process? What is the relationship between informational feedback as a coordinating behavior and interdependence, interpretation, information, purpose and meaning? How in HCI does information feedback facilitate coordinating behavior?

\section{References}

Belkin, N. J., Cool, C., Stein, A., \& Theil, S. (1995). Cases, scripts and information-seeking strategies: On the design of interactive information retrieval systems. Expert Systems With Applications, 9(3), 379395.

Ingwersen, P. (1992). Information retrieval interaction. London: Taylor Graham.

Ingwersen, P. (1996). Cognitive perspectives of information retrieval interaction: Elements of a cognitive IR theory. Journal of Documentation, 52(1), 3-50.

Kuhlthau, C. (1993). Seeking meaning: A process approach to library and information services. Norwood, NJ: Ablex Publishing.

Saracevic, T. (1996). Interactive models in information retrieval (IR): A review and proposal. Proceedings of the 59th Annual Meeting of the American Society for Information Science, 33, 3-9.

Saracevic, T. (1997). Extension and application of the stratified model of information retrieval interaction. Proceedings of the 60th Annual Meeting of the American Society for Information Science, 34, 313327.

Spink, A. (1997a). Information science: A third feedback framework. Journal of the American Society for Information Science, 48(4), 741-760.

Spink, A. (1997b). A study of interactive feedback during mediated information retrieval. Journal of the American Society for Information Science 48(5), 382-394.

Spink, A. (1998a). Toward a feedback model for informatics: Nature and manifestations of information feedback. Proceedings of SCI 98:Systematics, Cybernetics \& Informatics: Orlando, Florida. July 1998 (pp. 75-92).

Spink, A. (1998b). Toward a theoretical framework for information retrieval (IR) within an information seeking context. Proceedings of the 2nd International Information Seeking in Context Conference, August 12-15, 1998. Sheffield, UK: University of Sheffield, Department of Information Studies.

Spink, A., Greisdorf, H., \& Batemen, J. (1998). From highly relevant to not relevant: Examining different regions of relevance. Information Processing and Management, 34(5), 599-622.

Spink, A., \& Losee, R. M. (1996). Feedback in information retrieval. Annual Review of Information Science and Technology, 31, 33-78.

Spink, A., \& Saracevic, T. (1998). Human-computer interaction in information retrieval: Nature and manifestations of feedback. Interacting With Computers: The International Journal of Human-Computer Interaction.

Wilson, T. D. (1997). Information behavior: An interdisciplinary perspective. Information Processing and Management, 33(4), 551-572 